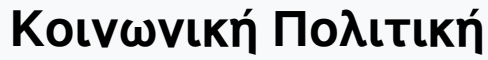

Tóp. 9 (2018)

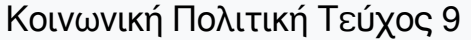

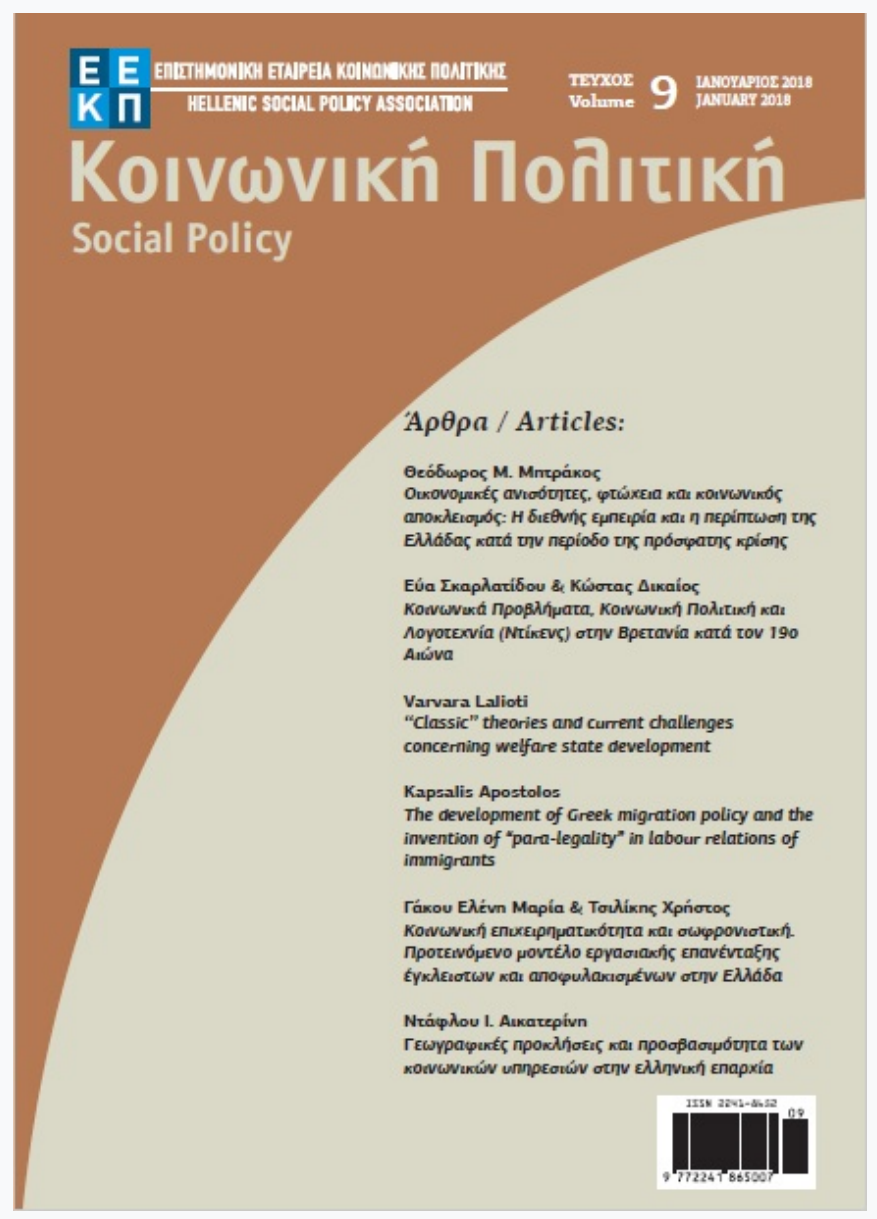

\section{Lipsky (1980), Street-Level Bureaucracy: The Dilemmas of the Individual in Public Service, Russell Sage Foundation, New York.}

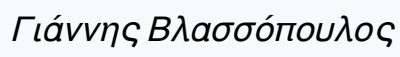

doi: $10.12681 /$ sp.15989

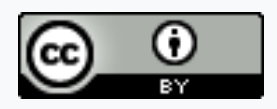

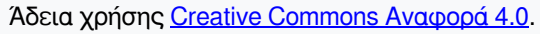

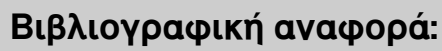

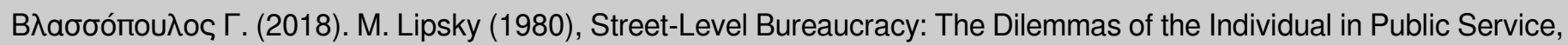

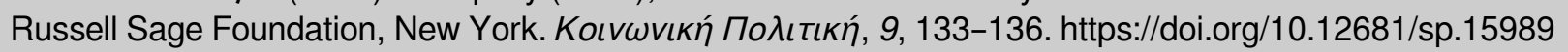




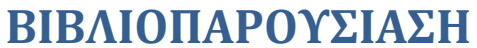

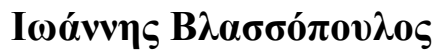

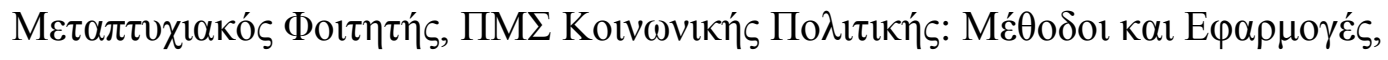

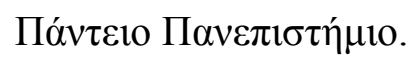

\section{Lipsky (1980), Street-Level Bureaucracy: The Dilemmas of the Individual in Public Service, Russell Sage Foundation, New York.}

To $\beta$ ß $\beta$ ío «Street-Level Bureaucracy: The Dilemmas of the Individual in Public

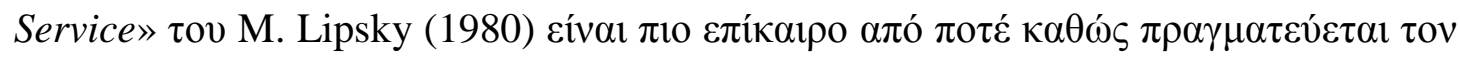

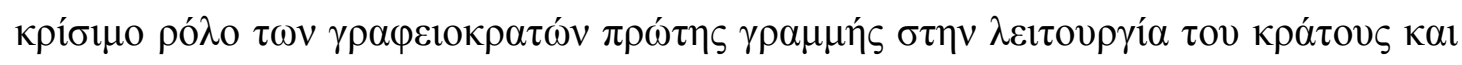

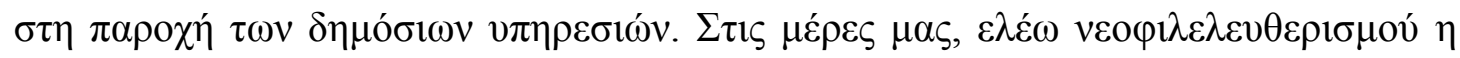

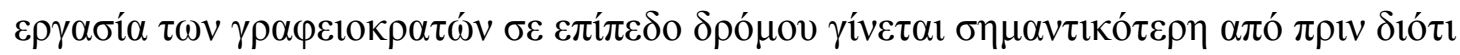

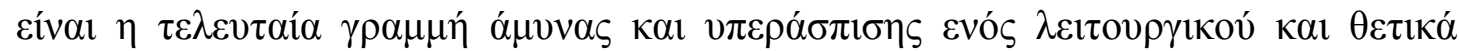
$\alpha \pi \circ \tau \varepsilon \lambda \varepsilon \sigma \mu \alpha \tau$

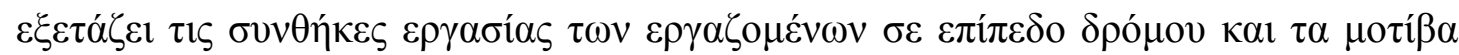

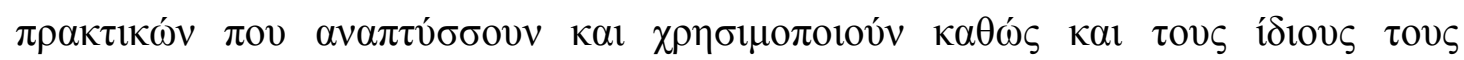

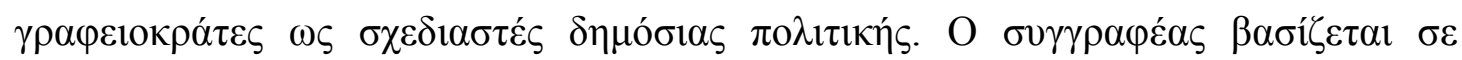

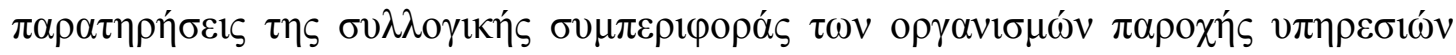

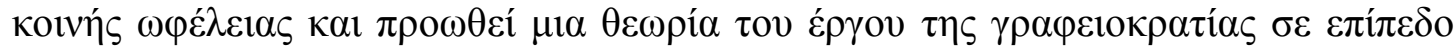

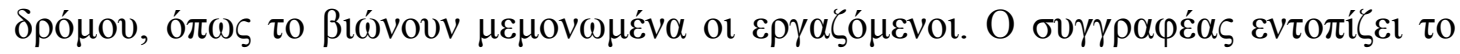

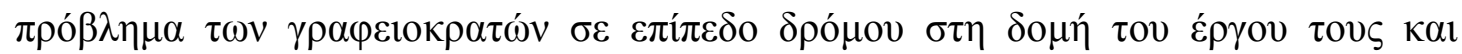

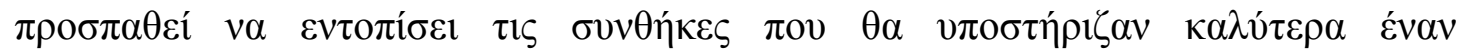

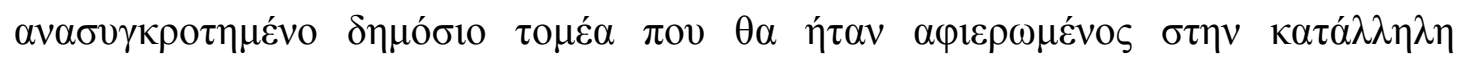

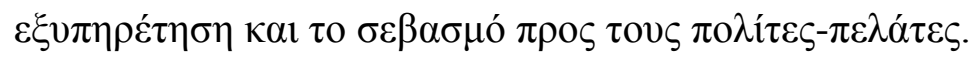

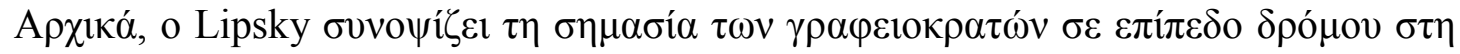

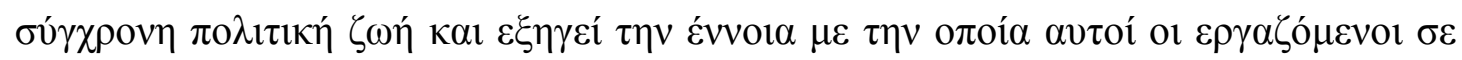

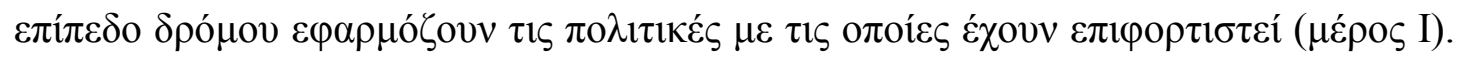

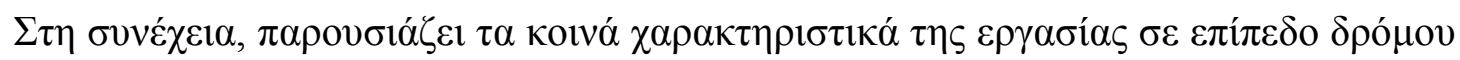

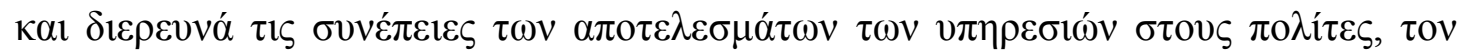

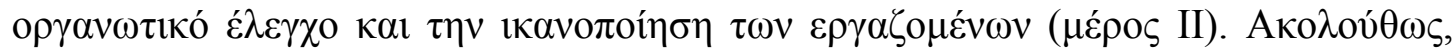




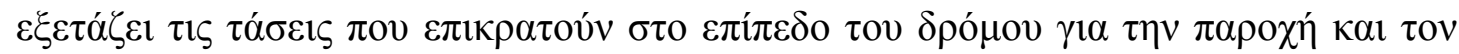

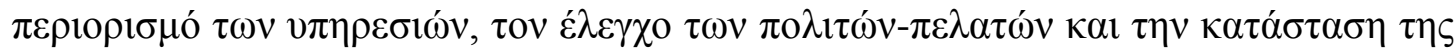

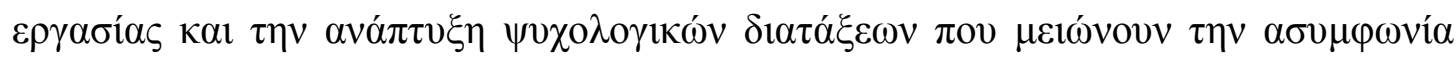

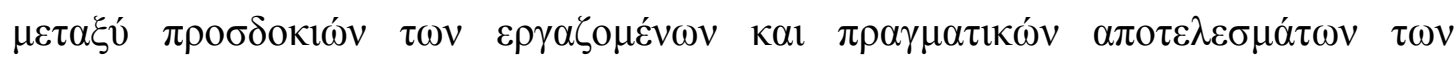

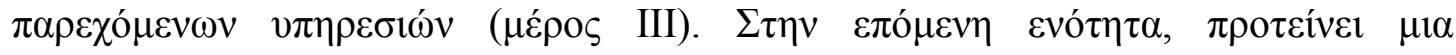

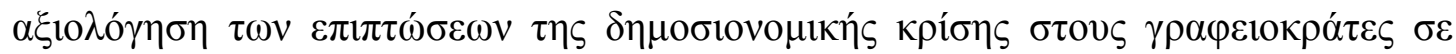

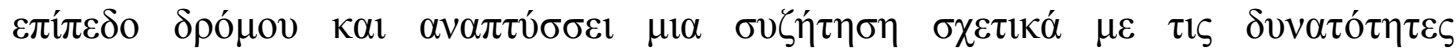

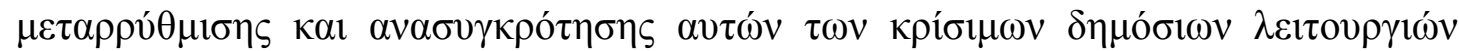
( $\left.\mu \varepsilon ́ \rho \circ \mathrm{s}_{\mathrm{IV}}\right)$.

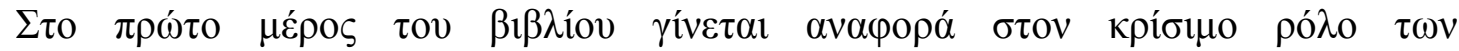

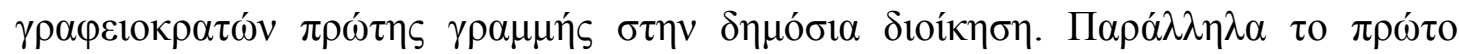

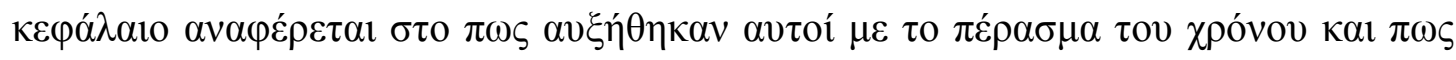
$\varepsilon \pi \omega \varphi \varepsilon \lambda \eta ́ \theta \eta \kappa \alpha \nu$ a

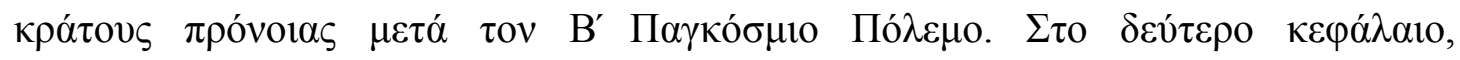

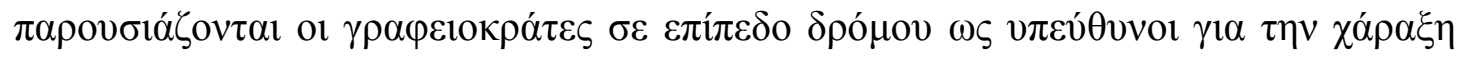

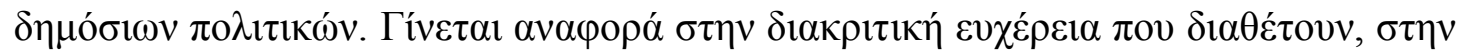

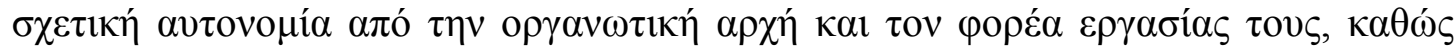

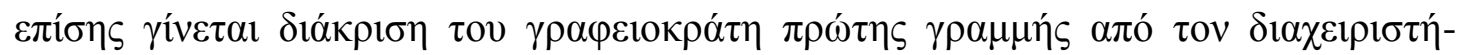

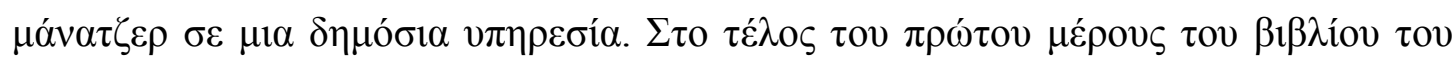

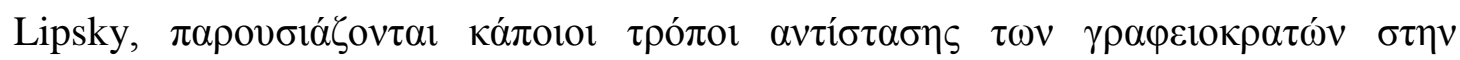

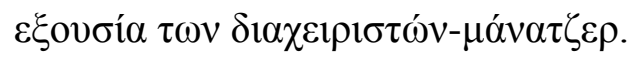

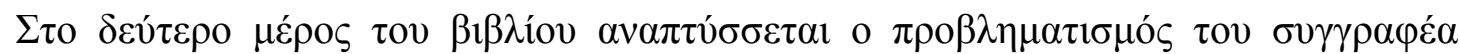

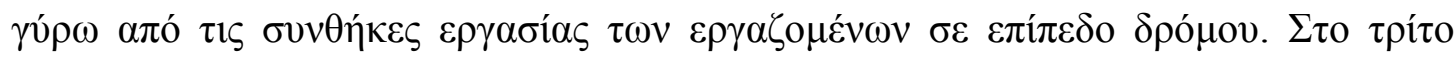

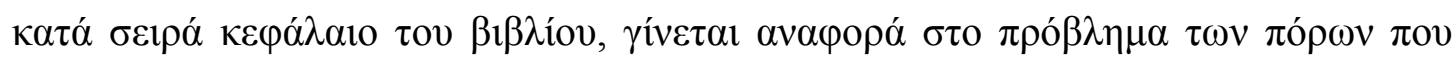

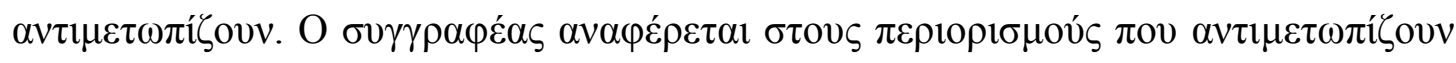

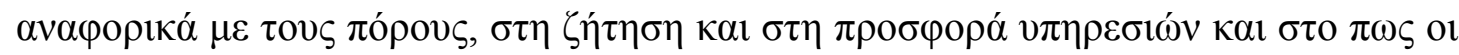

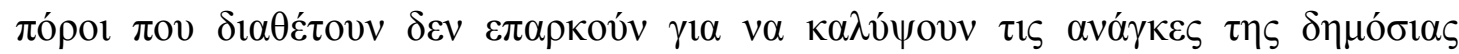

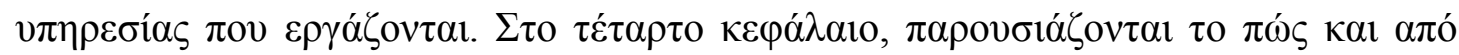

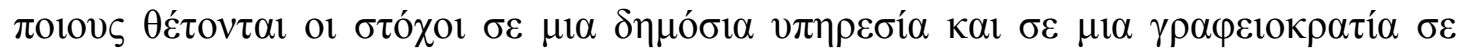

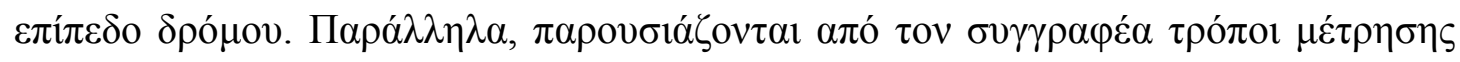

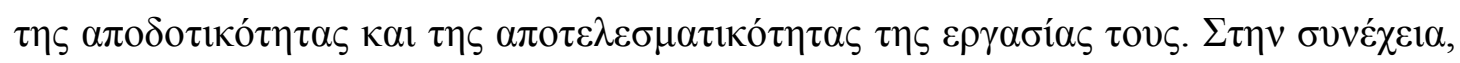

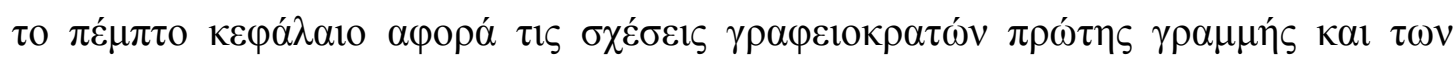

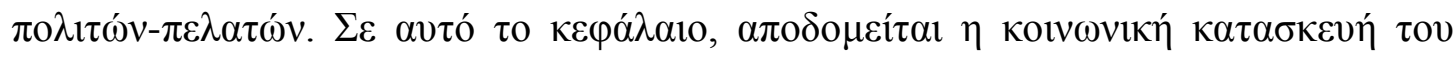




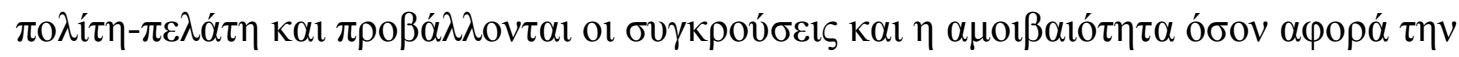

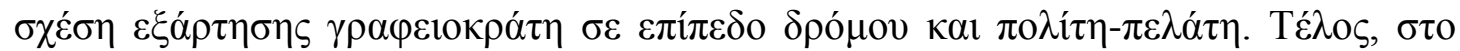

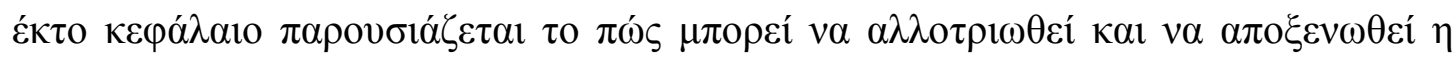

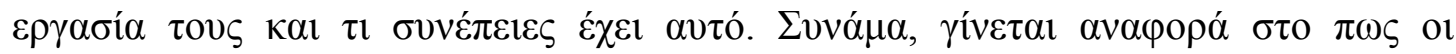

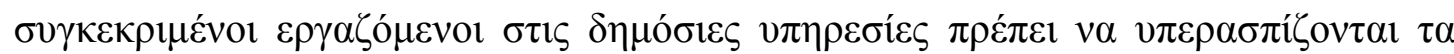

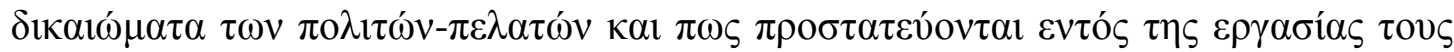

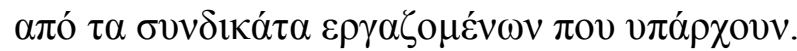

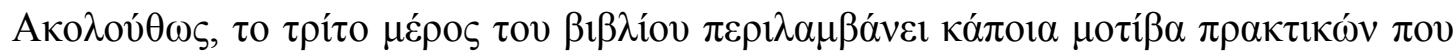

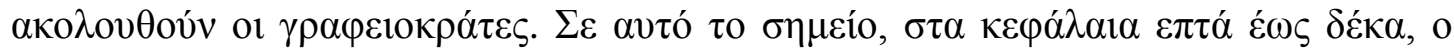

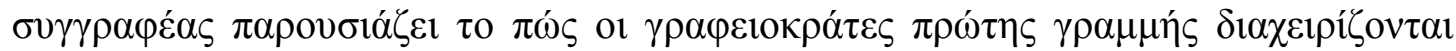

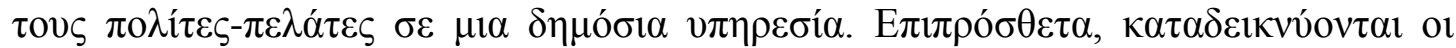

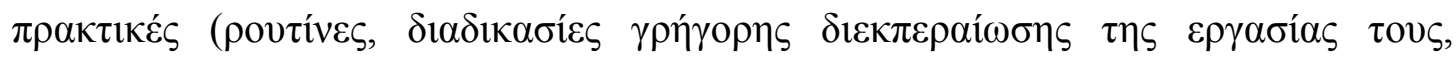

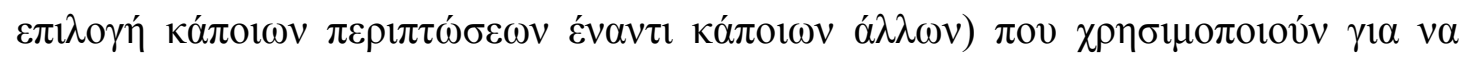

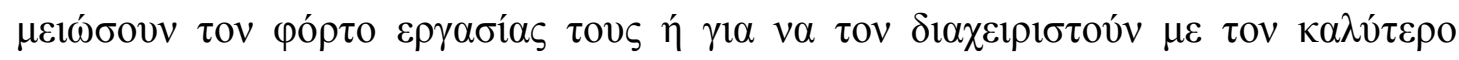

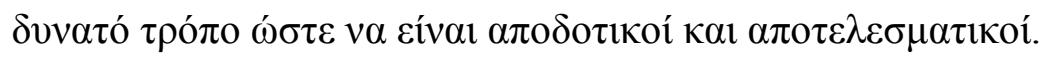

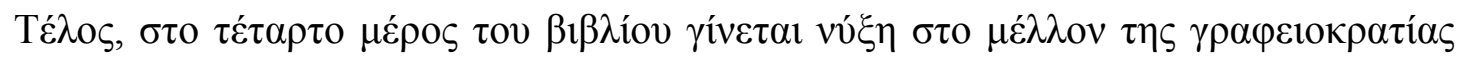

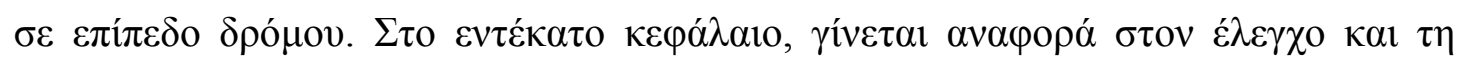

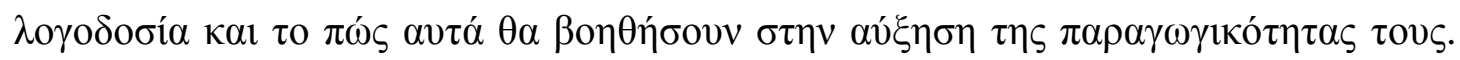

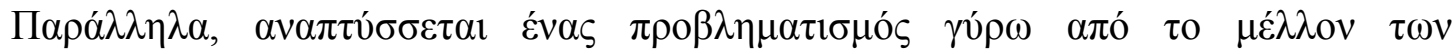

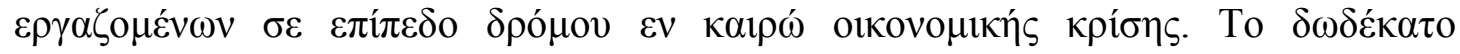

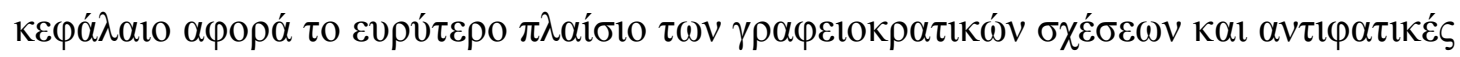

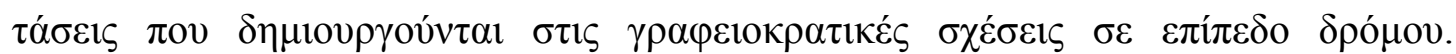

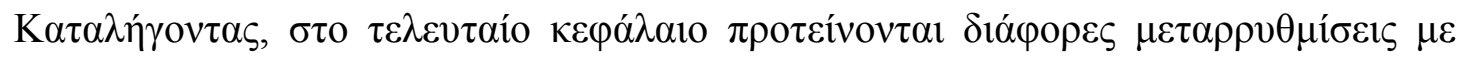

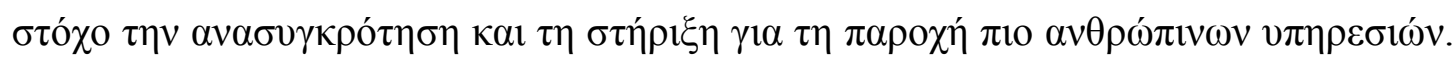

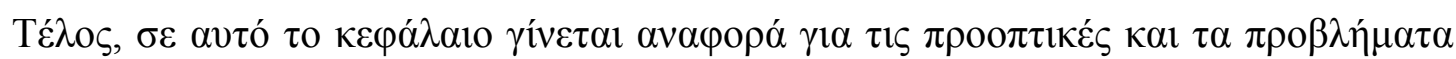

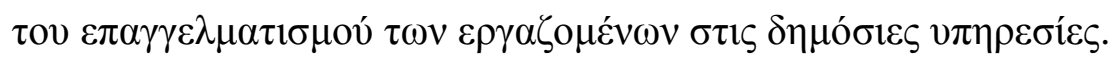

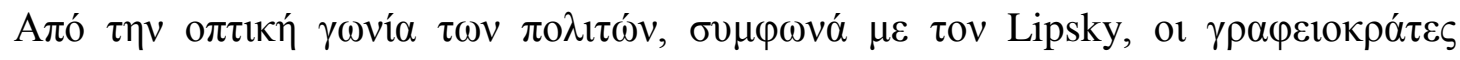

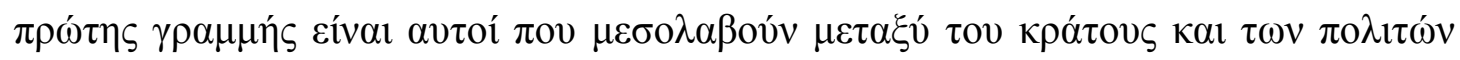

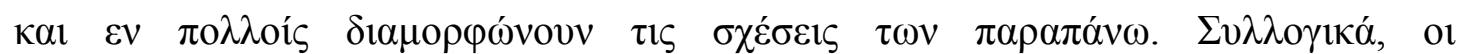

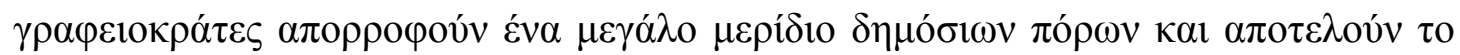

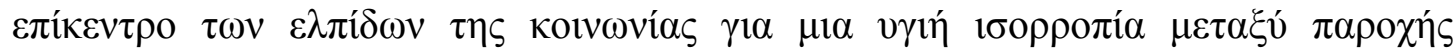

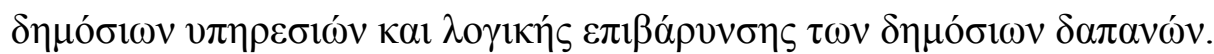




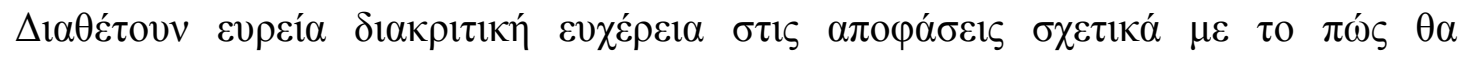

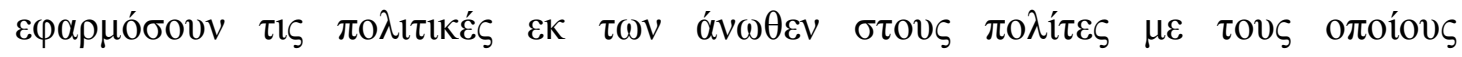

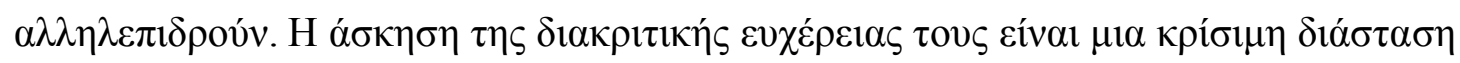

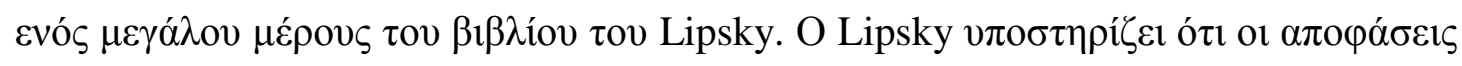

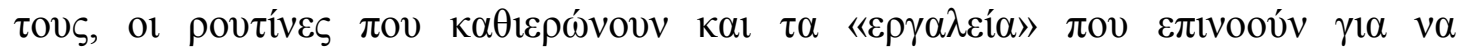

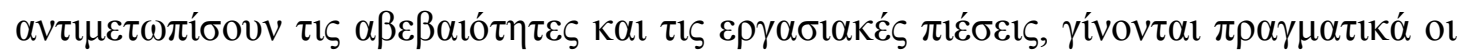

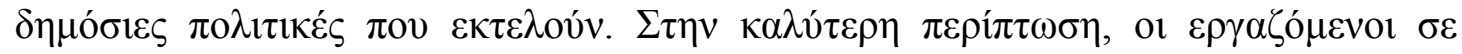

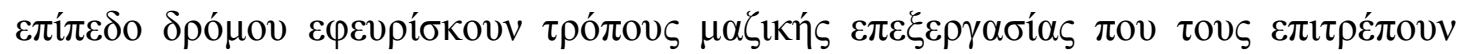

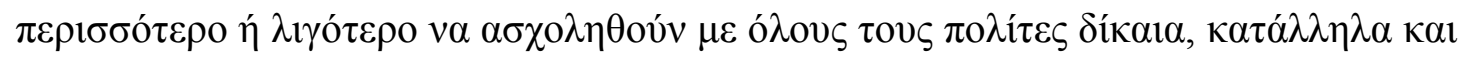

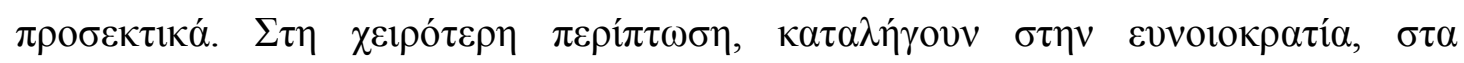

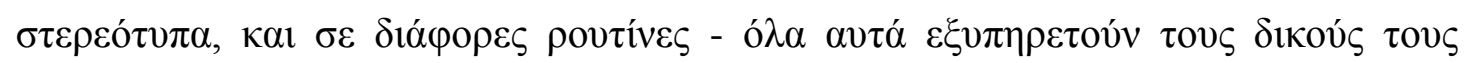

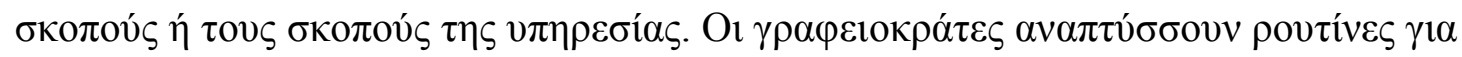

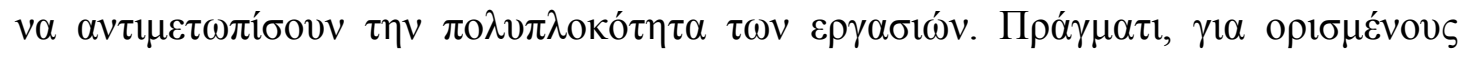

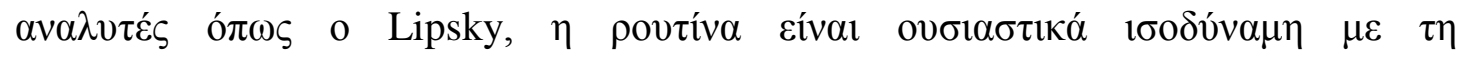

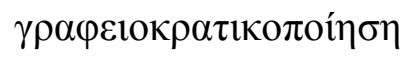

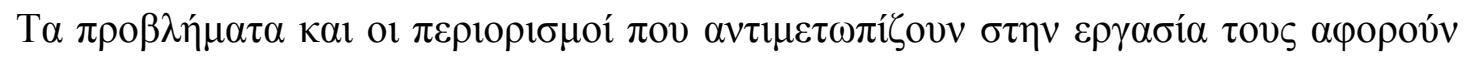

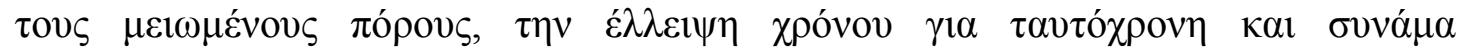

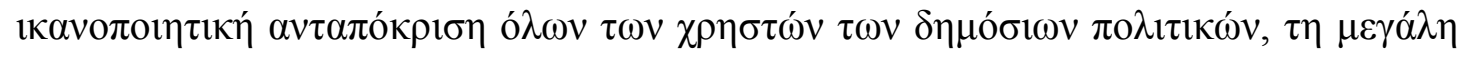

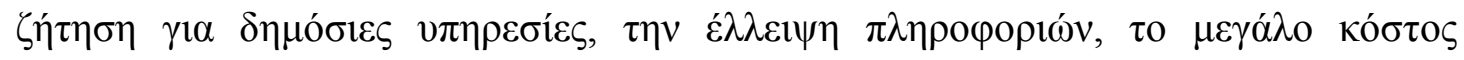

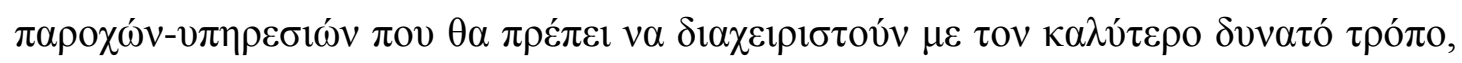

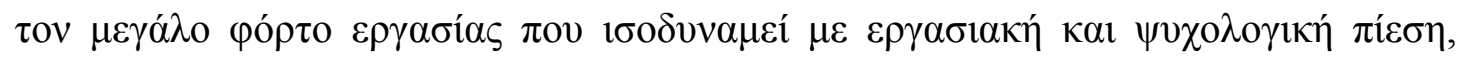

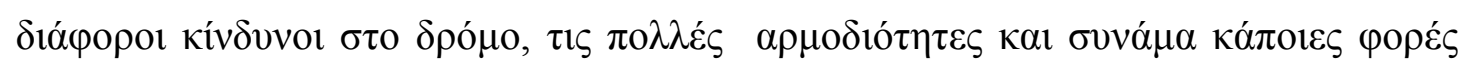

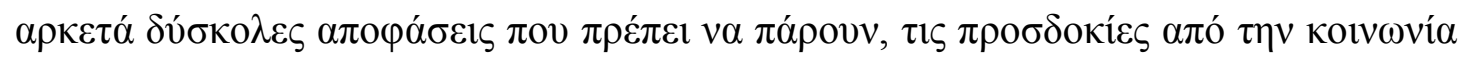

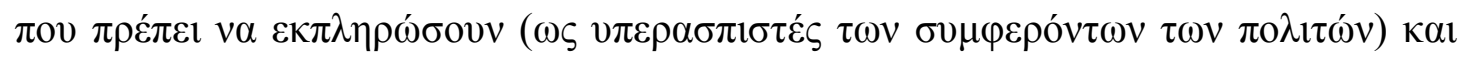

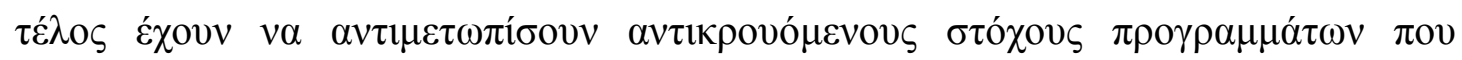

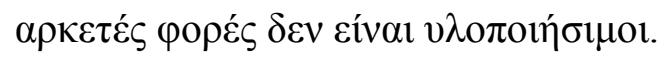

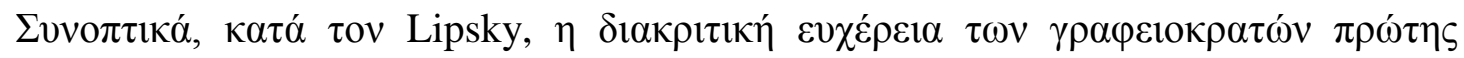

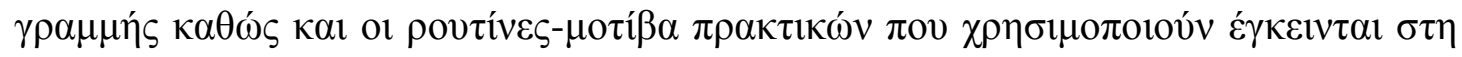

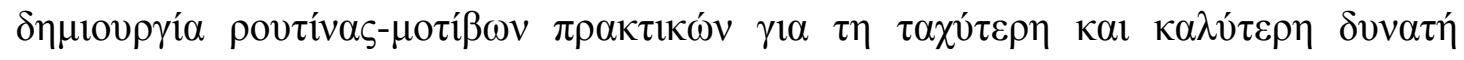

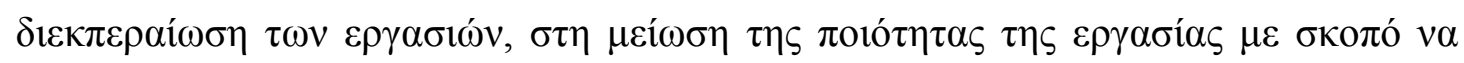

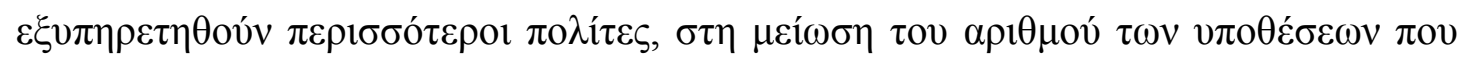

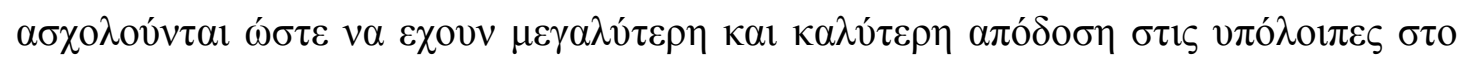

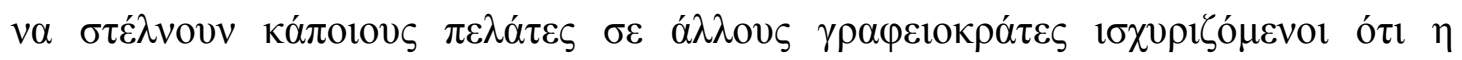




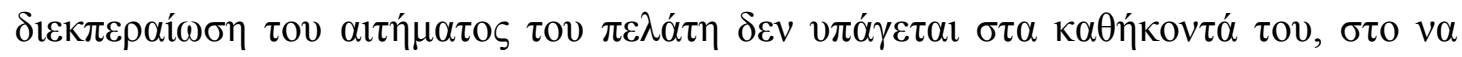

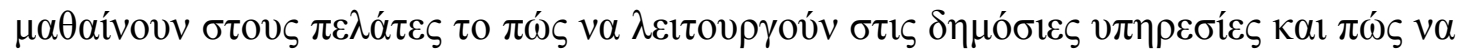

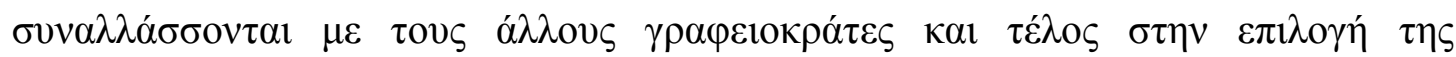

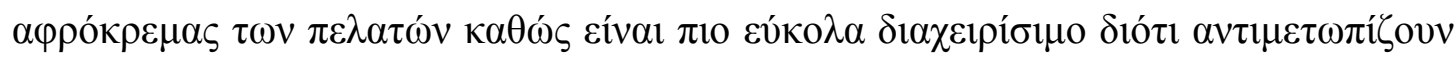

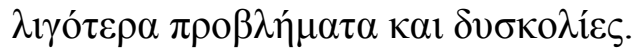

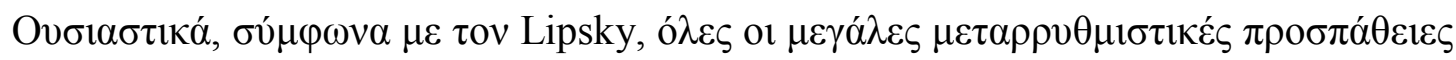

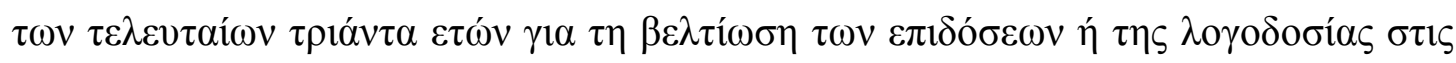

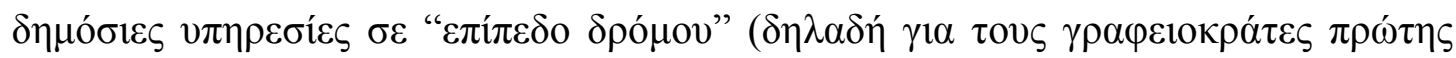

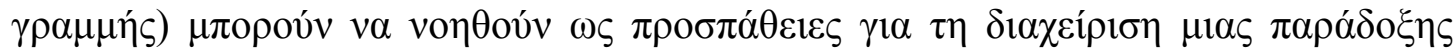

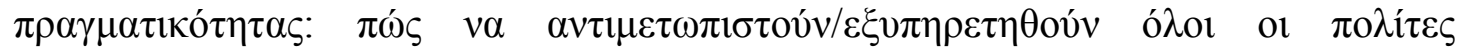

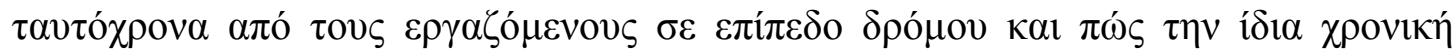

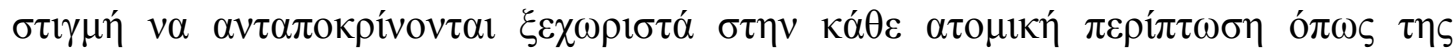

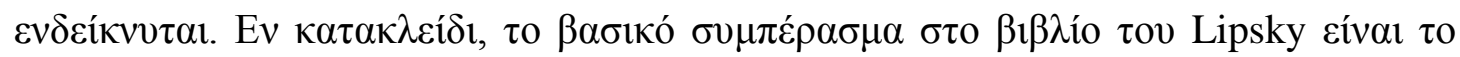

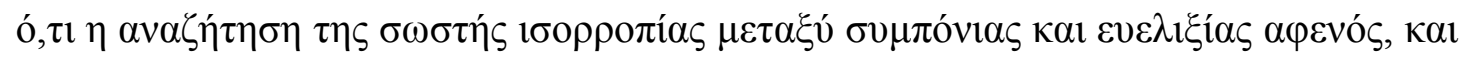

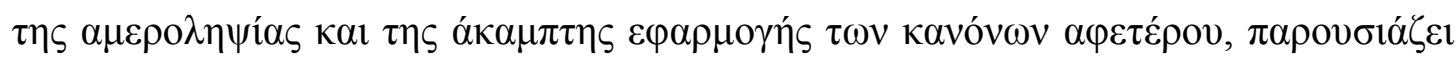

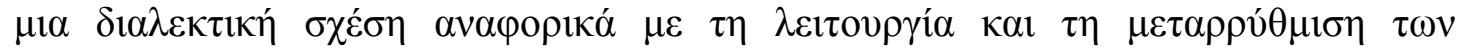
$\delta \eta \mu o ́ \sigma 1 \omega v ~ v \pi \eta \rho \varepsilon \sigma 1 \omega ́ v$. 